APOLINÁRIO, J. A. F. Nietzsche e Kant: sobre a crítica e a fundamentação da moral. Recife: Ed. da UFPE, 2012.

\title{
Rodrigo Barbosa
}

Mestrando em Filosofia na Pontifícia Universidade Católica do Paraná (PUCPR), Curitiba, PR - Brasil, e-mail: semcentro@gmail.com

O livro de José Antônio Apolinário, intitulado Nietșsche e Kant: sobre crítica e a fundamentação da moral, lançado em 2012 pela Editora Universitária da UFPE e prefaciado por Vicenzo Di Matteo, apresenta-se na eminente tarefa de "aproximação"e "diferenciação" entre dois importantes pensadores alemães em relação a temas intricados como a crítica e a Moral. A hipótese central do livro é a de que a crítica em Nietzsche pode ser compreendida como um "redimensionamento do conceito de critica kantiano" (p. 18). Nesse sentido, o trabalho de "aproximação" e "diferenciação" entre o pensamento de autores tão complexos faz que Apolinário se utilize de uma "metodologia descritivo-analítica" (p. 19). Isso acontece a partir de uma demarcação textual que recobre, por um lado, os prefácios de Critica da Razãa Pura e Fundamentacão da metafisica dos costumes, de Kant e, por outro lado, as obras Aurora, Além do bem e do mal e Genealogia da Moral, de Nietzsche.

Estruturalmente elaborado de modo a facilitar essa difícil tarefa, o texto se organiza em três partes que, como unidades temáticas, permitem ao leitor o acesso a temas melindrosos em ambos os pensadores. $\mathrm{O}$ primeiro capítulo versa sobre o conceito de "crítica" no pensamento de 
Imannuel Kant que aponta, em certa medida, para o tratamento posterior do tema da "fundamentação da moral". No segundo capítulo, é investigado o "conceito nietzschiano de crítica", sua relação com os "valores" e a noção de "Genealogia da Moral" no pensamento de Friedrich Nietzsche. Por fim, após explicitar a necessidade de "redimensionamento da crítica" que a noção de genealogia em Nietzsche pressupõe, no terceiro capítulo, realiza uma espécie de balanço ou avaliação de um diagnóstico da "moral kantiana" e sua "fundamentação metafisica" a partir de uma perspectiva nietzschiana. Desse modo, o roteiro dos capítulos se estrutura de modo a clarificar ao leitor o objetivo fundamental do trabalho que consiste em "investigar as justificativas de Nietzsche para uma oposição radical ao modelo crítico kantiano e a fundamentação da moral dele decorrente" no intuito de demonstrar "os porquês de um redimensionamento do conceito de crítica" (p. 18). Vejamos alguns pontos específicos de como tal objetivo é realizado.

O primeiro capítulo denominado "Crítica e Fundamentação da Moral em Kant: da Crítica da Razão Pura à Fundamentação da Metafísica dos Costumes" é distribuído em cinco itens que direcionam a argumentação de um detalhamento etimológico semântico do conceito de "crítica" aos "aspectos centrais da moral em Kant". O autor destaca a importância de traçar o sentido "originário" do conceito de crítica, discorre sobre o sentido negativo de crítica sintetizado pela metáfora da "terraplanagem kantiana" (p. 29), identifica o "fundamento" e a "fundamentação" provenientes de uma espécie de exigência interna da própria "crítica", e ainda a demarcaşão realizada por Kant a fim de identificar o "âmbito próprio da moralidade". Em todos esses elementos e na justaposição desses argumentos, o propósito de Apolinário é mostrar como a noção de "crítica" em Kant conduz ao "fundamento" no sentido de "buscar e fixar o princípio supremo da moralidade" (p. 40).

No capitulo segundo, intitulado "Crítica e Genealogia da Moral em Nietzsche: entre a Aurora e a Visada Genealógica", a hipótese de Apolinário é a de que há um "redimensionamento da crítica" por parte de Nietzsche. Essa hipótese é defendida a partir da elaboração de argumentos que passam pela identificação do "conceito de crítica", pela discussão acerca dos "valores" e pelo entrelaçamento destes à "noção de Genealogia". De acordo com o autor, ao "modificar o papel da filosofia", Nietzsche "propõe uma crítica que venha aferir o valor entranhado nos valores" (p. 56). Nesse sentido, essa definição abarca a "exigência" fundamental do conceito 
de crítica em Nietzsche, identificado por Apolinário: a tarefa de "crivar o valor dos valores" de modo a identificar que toda "avaliação faz referência a um valor" (p. 56).

Consequentemente, é exatamente o "posicionamento afirmativo da crítica nietzschiana" que oferece o reconhecimento do "elemento diferencial" do conceito de crítica em Nietzsche que possibilita que a esfera da "criação" venha à tona na relação "destruição-criação" inerente ao processo da crítica. Assim, Apolinário antecipa alguns elementos que correspondem ao "olhar nietzschiano" sobre as coisas. Esse mesmo olhar se constitui como um esboço de algumas estratégias do pensamento de Nietzsche. Nesse sentido, explicita as "matrizes" dessa "filosofia antimetafísica" de Nietzsche, em sua especial disposição para com os "moralistas franceses" e - com as devidas rubricas -, para com o "positivismo" do final do século XIX (p. 66). É desse modo que encontramos certa proveniência do "método genealógico", em que se tem o esforço de demonstrar que "os valores são construídos a partir de avaliações humanas, bastante humanas" (p. 66).

A continuidade a essa exposição, situando especificamente o problema dos valores, é realizada na medida em que Apolinário destaca que a "retratação da moral" feita por Nietzsche não é de modo algum uma "edificação" de valores, mas antes "uma profunda estigmatização" e "uma denúncia" (p. 71). Para tanto, Apolinário analisa especialmente os textos de Aurora e Genealogia da Moral. Nesse ponto, o autor explicita de que modo Nietzsche apresenta a moralidade triunfante do Ocidente sobre essa forma caduca de sujeitamentopela obediência. Através da análise de Aurora, Apolinário indica como, já numa "propedêutica análise genealógica", Nietzsche critica a moral do sujeitamento, indicando que o que se tem na origem desse processo de acostumamento do costume, é "o conceito-chave da obediência" (p. 74).

Ademais, a crítica de Nietzsche, como demonstra Apolinário, culmina na crítica à moral cristã, uma vez que o filósofo do martelo indica uma espécie de "tática cristã" que consiste na "prática do inculcamento, da subversão pela substituição do significado" (p. 78) no âmbito dos "instintos vitais", por exemplo, ligados à sexualidade. Em relação à Genealogia, Apolinário destaca como a "genealogia" enquanto procedimento filosófico aparece em seu "ápice" de realização investigativa nas três dissertações que levam o título de Genealogia da Moral. A partir da definição e esclarecimento acerca dos objetivos do procedimento genealógico em Nietzsche, o autor 
inicia uma detida análise dos temas e concepções que eclodem da análise realizada por Nietzsche nesse texto.

Como um fechamento do segundo capítulo, Apolinário explicita os critérios elencados por ele que tornam plausível a compreensão da "crítica" de Nietzsche como um "redimensionamento da crítica" de Kant. Nesse sentido, o autor salienta o uso do termo "redimensionamento" e sua amplitude semântica, sem deixar de notar a apropriação que faz da intuição de Deleuze com o propósito de reinterpretar o conceito de crítica pela perspectiva de Nietzsche: "um dos móbeis principais da obra de Nietzsche é mesmo que Kant não empreendeu a verdadeira crítica, porque não soube colocar o problema em termos de valores" (p. 90). Seja propondo, a partir do comentário de Scarlett Marton, que a posição de Nietzsche se daria como uma "defesa do criticado" (p. 93), seja identificando, assim, a "insuficiência da crítica kantiana", Apolinário define o escopo de seu uso do termo "redimensionamento" como um "posicionamento crítico-iconoclasta" de "inversão" e "subversão" que teria sido realizado por Nietzsche. É tal "redimendionamento" que permite ao filósofo voltar sua "investigação na direção dos valores subjacentes às avaliações" e o próprio ato de avaliar valores como um "processo criador intrínseco à Filosofia" (p. 96). Esses elementos, de acordo com Apolinário, permitem assimilar o conceito de "crítica" em Nietzsche sob uma ótica mais apurada do que aquelas interpretações dos "tratados" de filosofia deram ao ligar Nietzsche e Kant no que se refere à "crítica".

No terceiro capitulo, "Nietzsche e os Dilemas da Moral Kantiana", Apolinário finaliza sua argumentação, realizando uma avaliação de alguns problemas específicos em relação ao pensamento de Kant. Um desses problemas é o do "fundamento" e a exigência de fundamentação que ali são examinados a partir da filosofia de Nietzsche. Nesse sentido, Apolinário postula que a busca por uma "fundamentação" está voltada para a manutenção dos valores da moral vigente, e que o trabalho do genealogista permite ver "que, no fundo, há a ausência de fundo" (p. 106). Consequentemente, "toda arquitetura fundacionista - e nesse caso, a de Kant - está a serviço da efetivação de 'certas' forças criadoras” (p. 107). Enfatizando ainda como consequência daquele tipo de busca por fundamentação o engendramento do "niilismo", Apolinário se mostra disposto, nessa parte do texto, a acentuar as discrepâncias entre o pensamento de Kant e Nietzsche sobre a moral. 
Por fim, é possível afirmar que o texto mostra uma coerência argumentativa identificada a partir de sua unidade temática que orienta os capítulos e itens em geral. Em seu conjunto, ao apresentar a realização efetiva da "crítica em sua inteireza", ponto em que Nietzsche se distanciaria do posicionamento de Kant, o livro de Apolinário permite que o leitor reconheça a plausibilidade de sua identificação dessa realização de Nietzsche com a ideia de um "redimensionamento do conceito de crítica". N'outras palavras, a legitimidade da hipótese de Apolinário é garantida na medida em que ele nos auxilia a compreender que o "redimensionamento da crítica" não se trata apenas de uma reavaliação do "programa gnosiológico" da crítica dos modernos, mas, para além desse escopo, passa pela reavaliação do estatuto da crítica no âmbito dos valores, da vida e do mundo.

Recebido: $12 / 12 / 2012$

Received: 12/12/2012

Aprovado: $15 / 12 / 2012$

Approved: 12/15/2012 